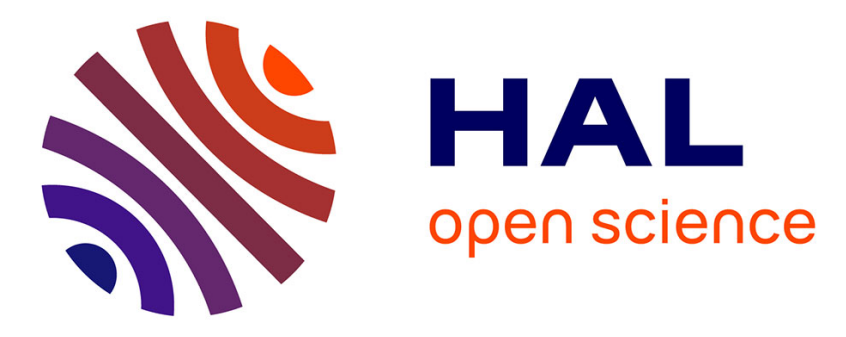

\title{
Microstructure Characterization of Oceanic Polyethylene Debris
}

\author{
Laura Rowenczyk, Alexandre Dazzi, Ariane Deniset-Besseau, Victoria \\ Beltran, Dominique Goudounèche, Pascal Wong-Wah-Chung, Olivier Boyron, \\ Matthieu George, Pascale Fabre, Clément Roux, et al.
}

\section{To cite this version:}

Laura Rowenczyk, Alexandre Dazzi, Ariane Deniset-Besseau, Victoria Beltran, Dominique Goudounèche, et al.. Microstructure Characterization of Oceanic Polyethylene Debris. Environmental Science and Technology, 2020, 54 (7), pp.4102-4109. 10.1021/acs.est.9b07061 . hal-02990067

\section{HAL Id: hal-02990067 https://hal.science/hal-02990067}

Submitted on 3 Dec 2020

HAL is a multi-disciplinary open access archive for the deposit and dissemination of scientific research documents, whether they are published or not. The documents may come from teaching and research institutions in France or abroad, or from public or private research centers.
L'archive ouverte pluridisciplinaire HAL, est destinée au dépôt et à la diffusion de documents scientifiques de niveau recherche, publiés ou non, émanant des établissements d'enseignement et de recherche français ou étrangers, des laboratoires publics ou privés. 


\section{Microstructure characterization of oceanic}

\section{2 polyethylene debris}

4 Laura Rowenczyk ${ }^{1}$, Alexandre Dazzi ${ }^{2}$, Ariane Deniset-Besseau ${ }^{2}$, Victoria Beltran ${ }^{3}$, Dominique

5 Goudounèche ${ }^{4}$, Pascal Wong-Wah-Chung ${ }^{5}$, Olivier Boyron ${ }^{6}$, Matthieu George $^{7}$, Pascale

6 Fabre $^{7}$, Clément Roux ${ }^{1}$, Anne Françoise Mingotaud ${ }^{1}$ and Alexandra ter Halle ${ }^{*}$

7 1. Laboratoire des IMRCP, Université de Toulouse, CNRS UMR 5623, Université Paul

8 Sabatier, 118 route de Narbonne 31062 Toulouse Cedex 9, France

9 2. Laboratoire de Chimie Physique (LCP), CNRS UMR 8000, Univ. of Paris-Sud, 10 Université Paris-Saclay, Orsay, France

11 3. IPANEMA, CNRS, Ministère de la Culture, UVSQ, USR3461, Université Paris-Saclay, 12 F-91192 Gif-sur-Yvette, France

13 4. CMEAB, IFRBMT, Université de Toulouse, 133 route de Narbonne, Toulouse, France 14 5. Aix Marseille Univ, CNRS, LCE, Marseille, France

15 6. Université de Lyon, CPE Lyon, CNRS, UMR 5265, Laboratoire de Chimie Catalyse 16 Polymères et Procédés (C2P2), Villeurbanne, France

17 7. Laboratoire Charles Coulomb (L2C), Univ Montpellier, CNRS, Montpellier, France.

*Corresponding author

KEYWORDS : polymer, nanoplastic, microplastic photodegradation, plastic weathering

Plastic pollution has become a worldwide concern. It was demonstrated that plastic breaks down to nanoscale particles in the environment, forming so-called nanoplastics. It is important to understand their ecological impact, but their structure is not elucidated. In this original work, we characterize the microstructure of oceanic polyethylene debris and compare them to the nonweathered objects. Cross-sections are analysed by several emergent mapping techniques. We highlight deep modifications of the debris within a layer a few hundred microns thick. The most 
intense modifications are macromolecule oxidation and a considerable decrease in the molecular weight. The adsorption of organic pollutants and trace metals is also confined to this outer layer. Fragmentation of the oxidized layer of the plastic debris is the most likely source of nanoplastics. Consequently nanoplastic chemical nature differ greatly from plastics.

\section{Introduction}

The scientific community has defined plastic pollution as a major worldwide concern. Indeed, since the introduction of plastic in the 1950s, 6300 million tons of plastic waste has been generated, a very large proportion of which has accumulated in landfills or the natural environment ${ }^{1}$. In addition to large microplastics (MPs, 1-5 mm), smaller plastic particles at the micrometre $(\mu \mathrm{Ps})^{2-4}$ and nanometre (nanoplastics, NPs) scales ${ }^{5-7}$ in the environment have been highlighted by recent studies. Because $\mu$ Ps and NPs exhibit very specific physico-chemical properties and reactivities, the evaluation of their potential toxicological impact require specific investigations $^{8}$. Primary MPs and $\mu$ Ps are defined as particles purposely manufactured at this scale, such as beads, fibres and pellets ${ }^{9}$. Secondary MPs and $\mu$ Ps result from the breaking down or erosion of larger objects. These mechanisms already occur early in the life of the object ${ }^{10}$. Primary NPs is still very anecdotic because there is no manufacturing at large scale, NPs mainly result from the degradation of macroscopic plastic objects ${ }^{6}$. Under laboratory conditions, the erosion of MPs presenting an advanced stage of weathering favours the formation of NPs ${ }^{11}$. A major source of plastic pollution is the mismanagement of municipal waste ${ }^{12}$, and fragmentation of these materials into micro- and nanosized particles is certainly a major degradation path ${ }^{13}$.

Plastic degradation involves hydrolysis, mechanical abrasion, thermal degradation, biodegradation and/or photodegradation ${ }^{10,14,15}$. Commonly used plastics are mostly prone to photodegradation ${ }^{16}$. Plastic photodegradation leads to structural modification of the polymer 
51 backbone, such as oxidation with the formation of carbonyl groups ${ }^{17}$, chain scission, radical 52 recombination and crosslinking ${ }^{18}$. Polymer photodegradation also leads to morphological alterations; the macromolecules can reorganize, and the crystallinity of the plastic often increases ${ }^{19}$. These physical transformations impact the mechanical properties of the material and favour breakdown and embrittlement ${ }^{20}$. Cracking, surface erosion and abrasion lead to the formation of $\mu$ Ps and NPs. Changes in the bulk properties of plastic in the ocean have been addressed $^{21-23}$, but the surface microstructure of plastic debris has not yet been thoroughly investigated.

The aim of this work is to provide new insights into modifications of the polymer microstructure upon weathering in the ocean and to elucidate the molecular structure of weathered plastics. Two oceanic plastic debris in polyethylene (PE) were selected because PE is the most commonly detected polymer in oceans ${ }^{29,35}$. The methodology of this study could be extended to investigate the microstructure of other weathered plastic such as polystyrene or polypropylene. The physico-chemical properties of the debris were compared to those of the original boxes, which allowed us to directly evaluate the impact of oceanic weathering. Cuttingedge technologies were deployed to precisely describe cross-sections and transverse sections of the material: micro-Fourier transform infrared ( $\mu$ FTIR) spectroscopy, infrared spectroscopy coupled to atomic force microscopy (nano-AFMIR) to measure the material oxidation,

69 fluorescence microscopy to monitor the adsorption of organic compounds and scanning/transmission electron microscopies coupled with energy dispersive X-ray 71 spectroscopy (EDS-SEM/TEM) to monitor the adsorption of inorganic compounds. As $\mu$ Ps and 72 NPs are generated from weathered macroscopic plastic debris, this study provides essential 73 information for the comprehension of the physico-chemical nature of $\mu$ Ps and NPs.

\section{Materials and methods}


Plastic debris was collected by boat in the North Atlantic sub-tropical gyre in June 2015 during the French $7^{\text {th }}$ Continent Expedition sea campaign ${ }^{21}$. Two of eight plastic debris samples of PE were selected here for the microstructure investigation. We selected a box of coffee and a box of cocoa powder and purchased new boxes for comparison (Figure SI 1).

\section{Surface and bulk characterization}

Characterizations by ATR-FTIR and measurements by DSC and SEC results were published in ter Halle et al. The PAH contents are presented in Bouhroum et al. ${ }^{24}$, and the metal levels are reported in Prunier et $\mathrm{al}^{25}$.

\section{Fourier transform infrared (FTIR) spectroscopies}

The $\mu$-FTIR mappings were obtained in transmission mode using a Hyperion 3000 (BRUKER) equipped with a focal plan array (FPA) detector. Background and sample spectra were acquired using 256 scans at a spectral resolution of $4 \mathrm{~cm}^{-1}$. Ten-micrometre-thick cross-sections were sealed in $\mathrm{KBr}$ pellets prior to observations. OPUS software allowed the CI maps to be drawn with the integration of the carbonyl absorption bands in the $1780-1660 \mathrm{~cm}^{-1}$ region and the methylene absorption band in the 1490 to $1420 \mathrm{~cm}^{-1}$ region. Spectra with high spectral and spatial resolution were obtained by AFMIR using a spectroscope. The spectra were generated with Analysis Studio software without any correction.

\section{AFM characterization}

Small-scale surface topographies were acquired by AFM using a Nanoscope V (Bruker) in contact mode. 
97 Cross-sections of the plastic samples were cut using a microtome with a diamond blade. Different thicknesses were obtained depending on the characterization technique. Crosssections of $10 \mu \mathrm{m}$ were used for the $\mu$-FTIR and light and fluorescence microscopies. EDSTEM required a thinner cut, and cross-sections of $150 \mathrm{~nm}$ were made specifically for this

101 analysis. For AFMIR, the surface of the section was basically flattened using the microtome, 102 and the measurements were performed directly on the plastic section. For EDS-MEB, the section was obtained by cryofracture.

\section{Light and fluorescence microscopic observations}

105 Light and fluorescence microscopies were performed using a digital slide imager NanoZoomer 2.0R.S (HAMAMATSU) equipped with an LX2000 $200 \mathrm{~W}$ Ultrahigh-pressure mercury lamp.

107 Observations were made at different excitation/emission wavelengths $\left(\lambda_{\mathrm{em}} / \lambda_{\mathrm{ex}}\right): 359 / 461 \mathrm{~nm}$, $108495 / 519 \mathrm{~nm}, 552 / 578 \mathrm{~nm}$ 554/566 and 649/666 nm. The images were corrected with NDP view 109 software to obtain a gain of 1.8 for the fluorescence observation.

111 TEM and scanning transmission electron microscopy (STEM) studies were performed using a

112 JEOL cold-FEG JEM-ARM200F operated at $200 \mathrm{kV}$ equipped with a probe Cs corrector 113 reaching a spatial resolution of $0.078 \mathrm{~nm}$. EDX spectra were recorded on a JEOL CENTURIO 114 SDD detector.

\section{Results and discussion}

116 Mesoplastics were collected in the North Atlantic sub-tropical gyre during the $7^{\text {th }}$ Continent 117 Expedition. Two debris were easily identified as cocoa and coffee powder packaging items 
named $\mathrm{M}_{1}$ and $\mathrm{M}_{2}$, respectively (Figure SI1). They were compared to two non-weathered

119 original items (named $\mathrm{I}_{1}$ and $\mathrm{I}_{2}$, respectively). Most observations obtained for one pair of items

120 (new and weathered) followed the same trend as those obtained for the other pair. Therefore,

121 for clarity, we discuss the results for $\mathrm{M}_{2}$ and $\mathrm{I}_{2}$ in the text, and $\mathrm{M}_{1}$ and $\mathrm{I}_{1}$ data are presented in

122 the Supplementary Information files.

\section{Characterization of plastic bulks and surfaces}

124 Table 1 summarizes the bulk and surface characteristics. For bulk characterization, we observed

125 no significant alteration of the melting points and crystallinity between the mesoplastics and

126 the original items. Polymer chain length is described by the number average molar mass $\left(\mathrm{M}_{\mathrm{n}}\right)$

127 and the weight average molar mass $\left(\mathrm{M}_{\mathrm{w}}\right)$, which can be measured by size exclusion

128 chromatography (SEC). The $\mathrm{M}_{\mathrm{n}}$ and $\mathrm{M}_{\mathrm{w}}$ values were both significantly smaller for $\mathrm{M}_{2}$

129 compared to $I_{2}:$ the $M_{n}$ value was reduced by a factor 2.

130
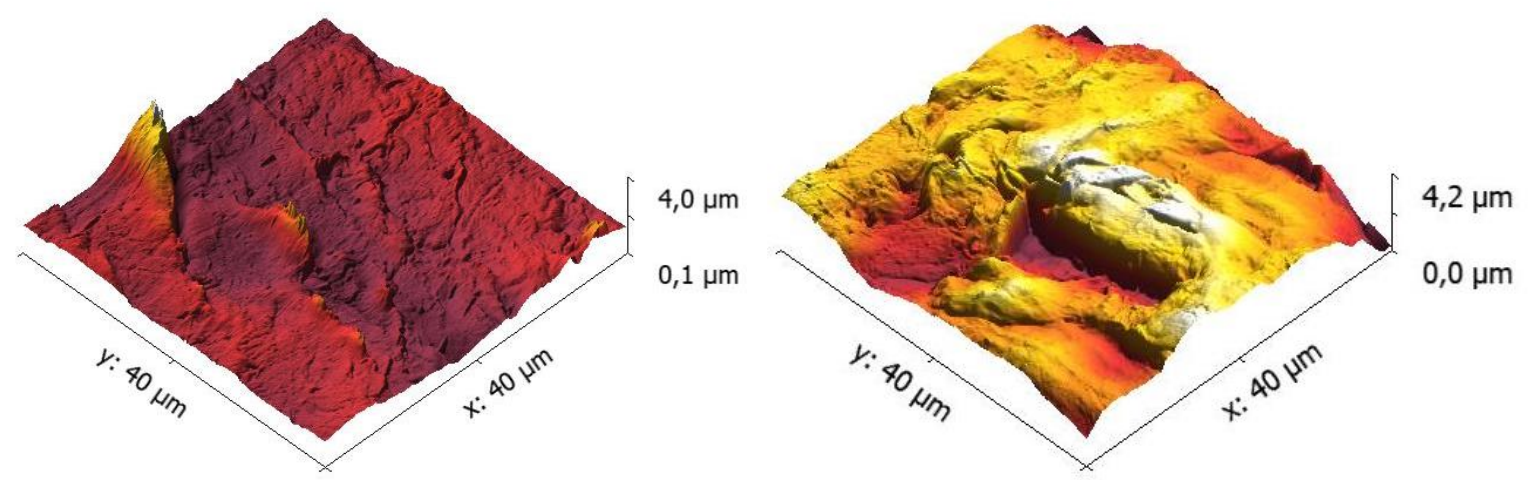

131 Figure 1: AFM characterization of the new coffee box $\left(\mathrm{I}_{2}\right)$ and the corresponding weathered

132 object $\left(\mathrm{M}_{2}\right)$. The root mean square roughness values for the original box and the weathered

133 object were $323 \mathrm{~nm}$ and $623 \mathrm{~nm}$, respectively.

134 For surface characterization, the mesoplastics presented a significantly higher carbonyl index

135 than the non-weathered item. Characterization of the plastic surface by atomic force microscopy 
136 (AFM) shows that there is a significant increase in the root mean square (RMS) roughness by at least a factor 2 (on $40 \mathrm{x} 40 \mu \mathrm{m}^{2}$ areas, Figure 1 and Figure SI2). This roughening is induced

138 by the appearance of micro-sized peaks at a scale that is typical of semi-crystalline

139 arrangement ${ }^{26}$. We also observe that the thickness of the mesoplastic is lower than that of the 140 original box (reduction of 15 to $20 \%$, Figure 2 and 4). A reduction in material thickness during 141 production to safe material resources may explain the difference in thickness but it can also be 142 envisaged that this thickness reduction is due to erosion; as it is observed upon polymer 143 photodegradation under controlled conditions ${ }^{27}$.

144 The total level of polycyclic aromatic hydrocarbons ( $\Sigma$ PAHs) in the plastic samples were below

145 the detection limit for original items (Table 1), whereas mesoplastics contained measurable 146 levels of $\Sigma$ PAHs in the range of $\mathrm{ng} / \mathrm{g}$. This finding is consistent with literature data ${ }^{28}$. The level 147 in $\mathrm{M}_{2}$ was seven times higher than that in $\mathrm{M}_{1}$. The important variations between $\Sigma \mathrm{PAH}$ levels 148 in plastic debris sampled in the same location have previously been noted ${ }^{29}$.

149 For metal concentrations, the focus was made on four metals found in noticeable amounts: Fe, $150 \mathrm{~Pb}$, Ti and $\mathrm{Cr}$. A detailed analysis of metal concentrations in the sample collected during this 151 campaign is given elsewhere ${ }^{25}$. The presence of metals in the original items is because some 152 metals are incorporated during the manufacturing process (such as $\mathrm{Ti}$ and $\mathrm{Fe}$ ) to improve plastic 153 properties. All metal concentrations were systematically higher in the mesoplastics than in the 154 original items because of sorption phenomena. The most explicit results were observed for $\mathrm{Pb}$ 155 and $\mathrm{Cr}$, as their quantities were 55000 and 1100 times higher in $\mathrm{M}_{1}$ than in $\mathrm{I}_{1}$, respectively. 156 Large variability from one sample to another was also observed ${ }^{30}$, and this variability is difficult 157 to rationalize.

158 Table 1: Characterizations of bulk material by ${ }^{\mathrm{a})}$ attenuated total reflectance FTIR, ${ }^{\mathrm{b})}$ calorimetry 
159 (DSC), and ${ }^{\mathrm{c})}$ SEC; ${ }^{\text {d) }}$ total level of polycyclic aromatic hydrocarbons measured by HPLC-FLD

160 (sum of eight PAH levels); and ${ }^{\text {e) }}$ metal concentrations determined by ICP-MS

\begin{tabular}{|c|c|c|c|c|c|}
\hline & & $\mathrm{I}_{1}$ & $\mathbf{M}_{1}$ & $\mathrm{I}_{2}$ & $\mathbf{M}_{2}$ \\
\hline \multirow{5}{*}{ 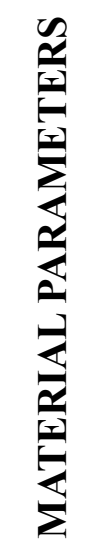 } & Carbonyl Index ${ }^{\text {a) }}$ & 0.1 & 0.7 & 0 & 0.3 \\
\hline & $\begin{array}{l}\text { Melting point }{ }^{\mathrm{b})} \\
\text { Endset }\left({ }^{\circ} \mathrm{C}\right)\end{array}$ & 141.8 & 135.7 & 142 & 142.7 \\
\hline & $\begin{array}{c}\text { Crystallinity }{ }^{\mathbf{b})} \\
(\%)\end{array}$ & 41 & 39 & 43 & 42 \\
\hline & $\begin{array}{c}\left.\mathbf{M}_{\mathbf{n}} \mathbf{c}\right) \\
\left(\mathrm{kg} \mathrm{mol}^{-1}\right)\end{array}$ & 21.0 & 10.9 & 12.3 & 7.1 \\
\hline & $\begin{array}{c}\left.\mathbf{M}_{\mathbf{w}} \mathbf{c}\right) \\
\left(\mathrm{kg} \mathrm{mol}^{-1}\right)\end{array}$ & 85.5 & 80.8 & 94.0 & 67.5 \\
\hline \multirow{5}{*}{ 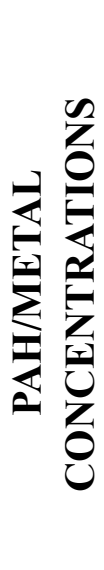 } & $\begin{array}{c}\left.\underset{\left(\mathrm{ng} \mathrm{g}^{-1}\right)}{\boldsymbol{\Sigma}}\right) \\
\text { PAHs d) }\end{array}$ & ND & 2.2 & ND & 15.3 \\
\hline & $\begin{array}{c}\mathbf{F e} \\
\left(\mu \mathrm{g} \mathrm{g}^{-1}\right)\end{array}$ & 1.1 & 19.2 & ND & $58.1^{*}$ \\
\hline & $\begin{array}{c}\mathbf{P b} \\
\left(\mu \mathrm{g} \mathrm{g}^{-1}\right)\end{array}$ & 0.05 & 2760.45 & ND & $0.02 *$ \\
\hline & $\begin{array}{c}\mathbf{T i} \\
\left(\mu \mathrm{g} \mathrm{g}^{-1}\right)\end{array}$ & 42.5 & 78.5 & ND & $8.8^{*}$ \\
\hline & $\underset{\left(\mu \mathrm{g} \mathrm{g}^{-1}\right)}{\mathbf{C r}}$ & 0.8 & 866.2 & ND & $3.0^{*}$ \\
\hline
\end{tabular}

$161 *$ Average of two values.

162

163 To summarize, surface characterization were more sensitive than bulk characterization to

164 highlights some structural modifications of the polymer upon weathering. While calorimetry

165 does not allow us to measure differences in the melting point or the percentage of crystallinity,

166 the molar masses $\left(\mathrm{M}_{\mathrm{n}}\right.$ and $\left.\mathrm{M}_{\mathrm{w}}\right)$ was more sensitive parameters. Both metals and organic

167 pollutants can be sorbed by plastic debris in large amounts.

168 Oxidation profile

169 For the microstructure investigation, cross-sections were obtained using different methods to 
170 produce samples with thicknesses adapted to each characterization technique (Figure SI 3). $\mu$ -

171 FTIR mapping of the cross-sections allowed us to obtain a cartography of the carbonyl index

172 (Figure 2). The coffee box sample $\mathrm{I}_{2}$ exhibited a low and uniform carbonyl index across the

173 whole cross-section (upper mapping in Figure 2). $I_{2}$ is not oxidized on its surfaces or at its

174 centre. In contrast, cross-section mapping of $\mathrm{M}_{2}$ highlights a highly oxidized external face, with

175 a deep oxidation gradient from the edge towards the centre. Oxidation was observed at depths

176 of up to $500-600 \mu \mathrm{m}$ within the material; one can note that the oxidation layer is heterogeneous

177 at the micrometre scale. The internal face appeared much less oxidized. The rate of oxygen

178 diffusion into the material presumably evolves with the material aging. With aging the surface

179 becomes more porous and could facilitate oxygen transport and further deep oxidation of the

180 debris.

181 AFMIR is a recently developed cutting-edge technique that combines the high spatial resolution

182 of an AFM and the chemical characterization offered by IR spectroscopy ${ }^{31}$. AFMIR presents a

183 high spatial resolution of ten nanometres. Spectra were acquired between 900 or $1350 \mathrm{~cm}-1$ and

$1841900 \mathrm{~cm}-1$. Punctual measurements $(30 \times 30 \mathrm{~nm})$ were performed at three different locations

185 along the cross-section (external and internal faces and centre).

186 The AFMIR spectra of $\mathrm{M}_{2}$ (Figure $2 \mathrm{~A}$ and SI4) indicated that the oxidation band was more

187 intense and broader than that of $\mathrm{I}_{2}$ and was shifted to $1712 \mathrm{~cm}^{-1}$. The broadening of the oxidation

188 band is explained by the presence of various oxidation products. As frequently reported in the

189 literature, photooxidation of PE generates ketones (peak at $1720 \mathrm{~cm}^{-1}$ ) in the initial step. In

190 addition, secondary processes lead to the formation of carboxylic acids $\left(1713 \mathrm{~cm}^{-1}\right)$, esters

$191\left(1735 \mathrm{~cm}^{-1}\right)$ and lactones $\left(1780 \mathrm{~cm}^{-1}\right)^{32}$. The absorption band at $1641 \mathrm{~cm}^{-1}$ is attributed to the

192 formation of double bonds during PE photodegradation. Both the oxidation and double bound

193 bands were detected in the three scanned regions of the macrodebris. Thus, even within the 
194 material, the products of photodegradation are detected. This finding is in agreement with the $195 \mu$ FTIR mapping that indicated a deep oxidation gradient from the edge towards the centre of 196 the material section. Those local IR absorption spectra also gives an information about the 197 crystallinity of the sample. The relative intensity of the $1473-1464 \mathrm{~cm}^{-1}$ peak may vary from 198 point to another. This might be an orientation effect generated during item production. 199 Furthermore, $\mathrm{M}_{2}$ shows a shoulder at $1438 \mathrm{~cm}^{-1}$ and several weak absorption bands at 13702001354 and $1303 \mathrm{~cm}^{-1}$. Generally, in pure crystalline product, 1354 and $1303 \mathrm{~cm}^{-1}$ (also called 201 amorphous bands ${ }^{33}$ ) weak bands are absent ${ }^{34}$ and the wagging mode of $\mathrm{CH}_{2}$ at $1370 \mathrm{~cm}^{-1}$ is 202 more intense. Figure 2 B. shows the IR response of crystalline hentriacontane for whom the 203 intensity the wagging mode at $1370 \mathrm{~cm}^{-1}$ is largely higher than the two other bands (1354 and $\left.2041303 \mathrm{~cm}^{-1}\right)$. When comparing the AFMIR spectra of M2 internal and external face we cannot 205 establish if one face is more crystalline than another. 

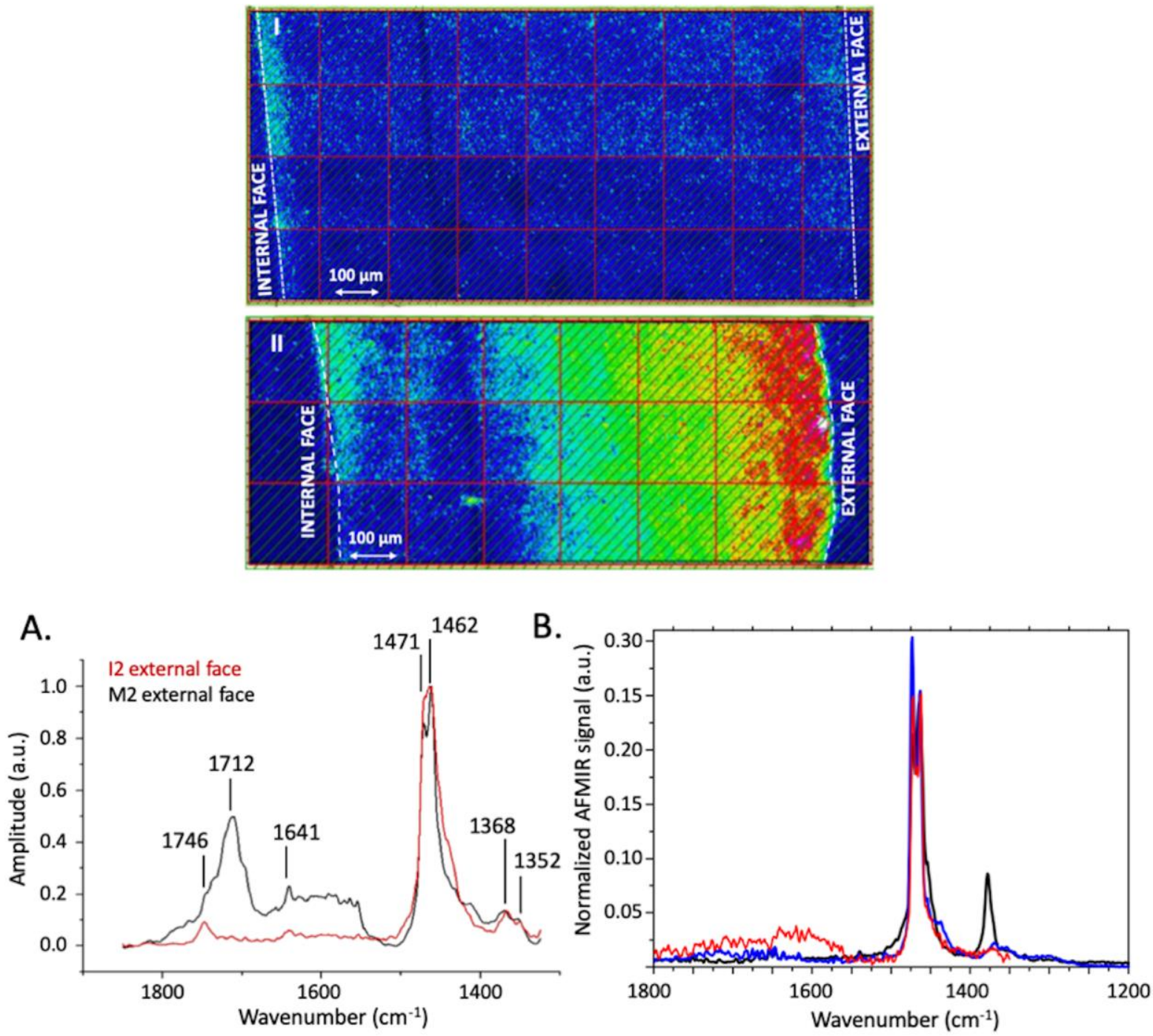

206

207 Figure 2: On the top: profile of oxidation obtained by $\mu$-FTIR with a representation of the 208 carbonyl index mapping of the new coffee box $\mathrm{I}_{2}$ (I) and the mesoplastic $\mathrm{M}_{2}$ (II). At the bottom : 209 A) local AFMIR spectra at the external face of the original coffee box (black) and the

210 mesoplastic (red) B) local AFMIR spectra of hentriacontane (black), internal face of the 211 mesoplastic (blue) and external face (red). The internal face appears less oxidized than the 212 external face.

\section{Calorimetric characterization of the transverse section}

214 For the microstructure investigation, the materials were sectioned transversally with a thickness 
of $100 \mu \mathrm{m}$ for DSC analysis (Supplementary Table 1). Bulk DSC measurements did not

216 highlight differences between the original items and the mesoplastics. While $\mathrm{I}_{2}$ edges were only 217 slightly more crystalline than the core material ( 1 to $2 \% \pm 1 \%$ ). The heterogeneity of $\mathrm{I}_{2}$ may be 218 a result of the manufacturing process (during injection moulding) or may be because the box 219 was exposed to light and already underwent slight photodegradation during storage. On the 220 contrary $\mathrm{M}_{2}$ external face was significantly different from the core material, while the internal 221 face presented fewer differences (Figure 3). The degree of crystallinity of the external face increased by $6 \%$ compared to that of the core material, and the melting point decreased by $3{ }^{\circ} \mathrm{C}$. The increase in crystallinity of plastics debris is explained by two parameters ${ }^{21}$. First explanation is that amorphous regions are more easily degraded. The second is that polymer degradation increases the mobility of the macromolecules, which can form new crystals. Due 226 to degradation, the molar mass of the chains is decreased, and therefore, the lamellae of the 227 folded chain are shorter. The shorter macromolecules are more mobile and this allow them to 228 crystalize $^{35}$. Consequently weathered polyethylene are more crystalline than pristine. The 229 resultant crystals obtained with a shorter folding length are smaller than the original crystals; 230 therefore, they exhibit a lower melting point (the lower the folding length is, the lower the 231 corresponding melting point) ${ }^{36-38}$. The observed lower melting point of the resulting materiel 232 indicates that the new crystals are of a lesser quality compare to the pristine ones. This can be 233 linked either to the lower molecular weight of the polymer chains involved or to a very slow 234 crystallization process. Since it is not possible to evaluate the aging time of the samples, we 235 cannot discriminate between these two posisbilities. We also noticed a significant narrowing of 236 the melting curves for the external faces compared to the rest of the material (Figure SI 5 and 237 6). 
The transverse sections were analysed by SEC (details in Supplementary Table 1). Generally

240 speaking, polymer photodegradation has a greater effect on the longer macromolecular chains,

241 and $\mathrm{M}_{\mathrm{w}}$ is more sensitive than $\mathrm{M}_{\mathrm{n}}$ to polymer chain scission. Mw data is presented here and $\mathrm{Mn}$

242 in supplementary material (Table SI 1). $\mathrm{I}_{2}$ presented an inhomogeneity in the molar mass, but

243 the variations in $\mathrm{M}_{2}$ were much greater. Again, the external face of the mesoplastics presented

244 the most intense modifications (Figure 3) with a $\mathrm{M}_{\mathrm{w}}$ value decreased by $80 \% . \mathrm{M}_{2}$ external face

245 presents a molecular weight of only $20000 \mathrm{~g} / \mathrm{mol}$.
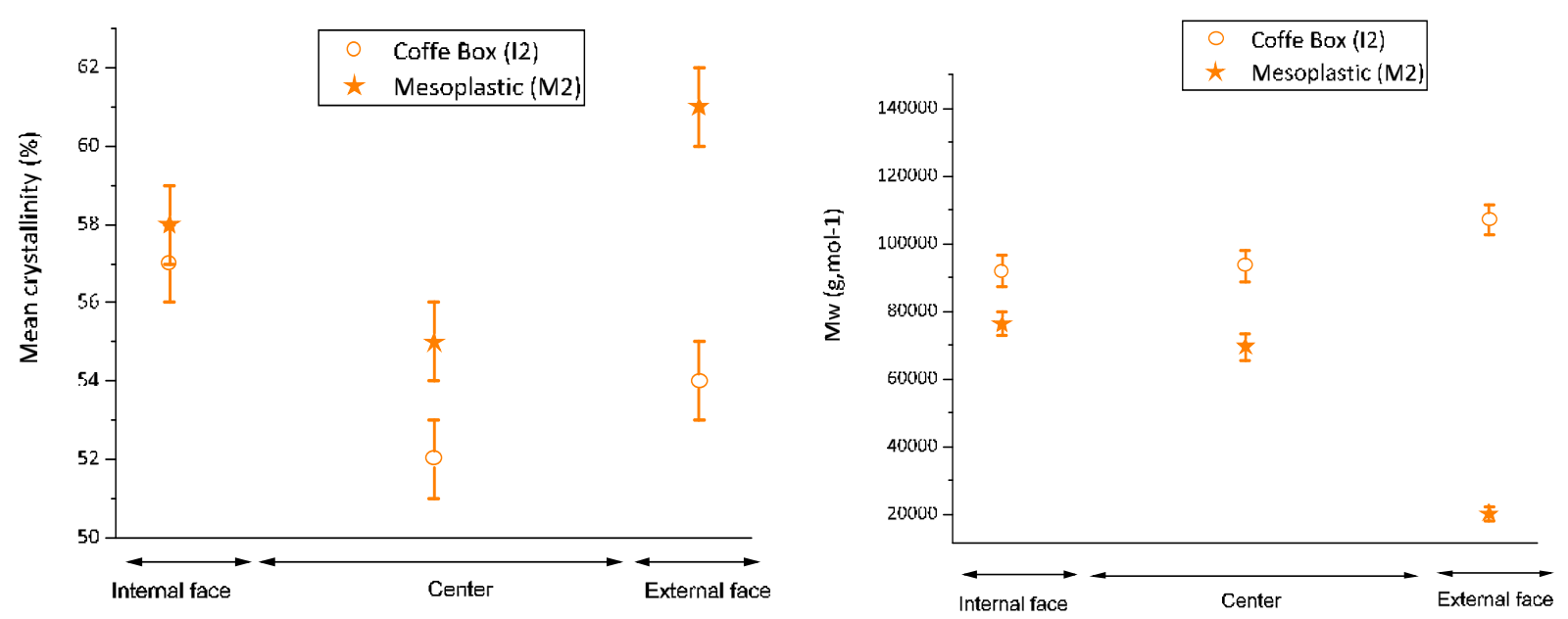

246 Figure 3: On the left, percentage of crystallinity and on the right weight average molar mass

$247\left(\mathrm{M}_{\mathrm{w}}\right)$. Data measured for the transverse sections (internal and external with a thickness of 100

$248 \mu \mathrm{m})$ and the core material (thickness of $1 \mathrm{~mm}$ ).

\section{Fluorescence and electronic microscopy of cross-sections}

250 When excited, $\mathrm{I}_{2}$ emitted an intense fluorescence, particularly at an excitation wavelength of $251554 \mathrm{~nm}$ (Figure 4). The initial fluorescence of $\mathrm{I}_{2}$ is attributed to additives, probably dyes of the 252 quinacridone family ${ }^{39}$. The fluorescence emitted by $\mathrm{M}_{2}$ at this excitation wavelength was much 253 less intense, which may be because a result of the additive either migrating out of the materials ${ }^{40}$ 254 or being degraded ${ }^{41}$. Although typical results for plastic additive desorption under normal 
255 conditions of use are generally known ${ }^{42,}{ }^{43}$, the desorption of additives under weathering 256 conditions has been less described.

257 At $359 \mathrm{~nm}$, although $\mathrm{I}_{1}$ and $\mathrm{I}_{2}$ were not fluorescent $\mathrm{M}_{1}$ and $\mathrm{M}_{2}$ (Figure 4 and SI 7 ) exhibited a 258 fluorescence gradient from the external face towards the centre in the range of 200 to $400 \mu \mathrm{m}$. 259 This fluorescence indicates the presence of new aromatic compounds in the material and could 260 be attributed to PAHs that present characteristic fluorescence ${ }^{44-46}$ with an excitation wavelength 261 between 255 and $365 \mathrm{~nm}$. This signal could also be attributed to marine dissolved organic 262 matter $^{47}$ or the products of degradation of additives within the plastic. It is important to note 263 that these fluorescent chemicals are sorbed within the first hundred microns of the materials 264 and could easily leach, for example, in the case of ingestion, where the $\mathrm{pH}$ conditions could 265 favour transfer to the organisms. 


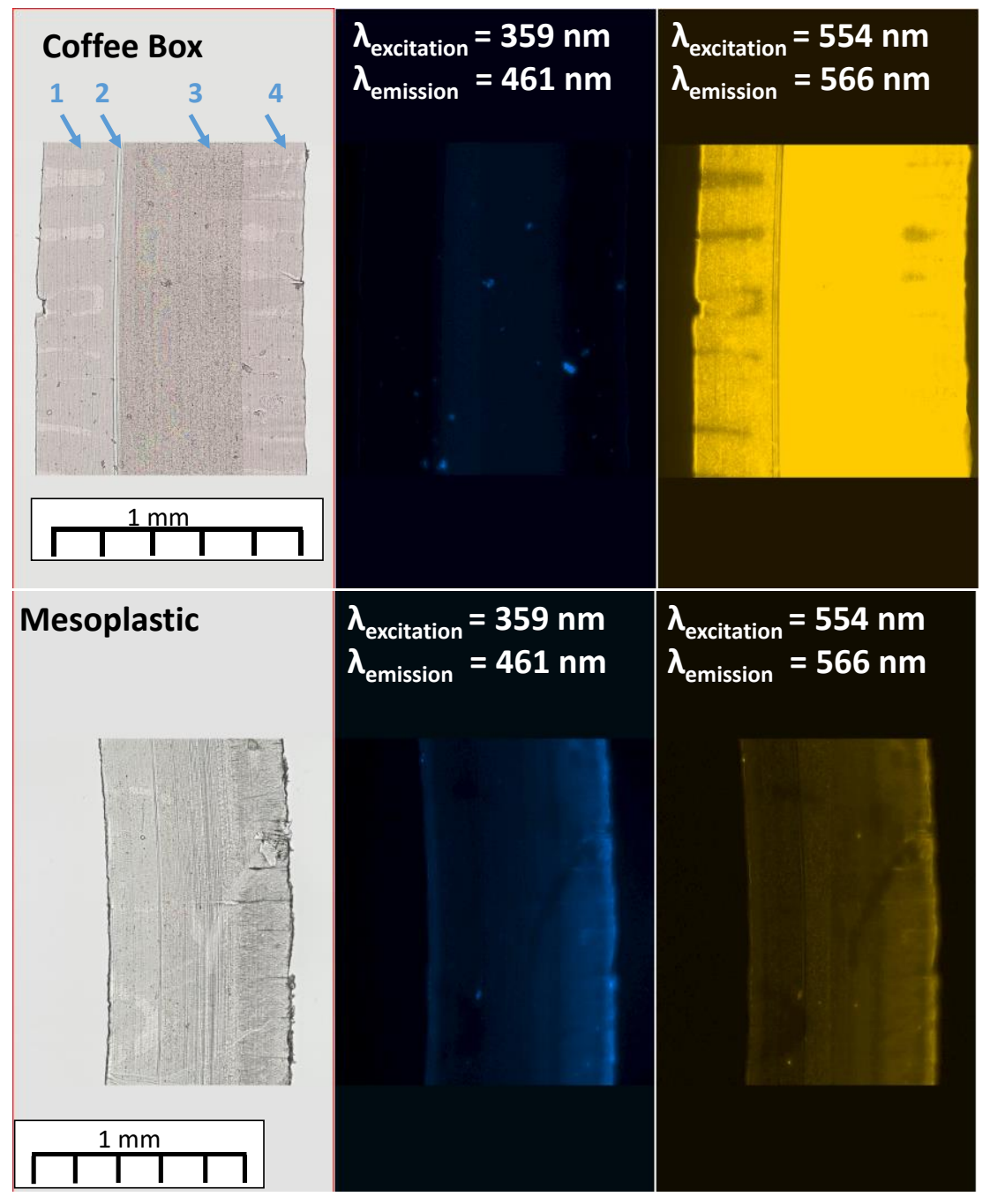

267 Figure 4: Microscopic observations of the new item $\left(\mathrm{I}_{2}\right)$ and the mesoplastic $\left(\mathrm{M}_{2}\right)$. On the left 268 is a bright field image, and on the right are fluorescence images.

269 The atomic composition of the cross-sections was characterized by EDS-TEM. Numerous Ca 270 and Ti ion-based particles were found in all four materials (Figure SI 8 to 10). Particles

271 containing calcium were between 5 and $10 \mu \mathrm{m}$, and Ti ion-based particles were larger (200 to $272500 \mathrm{~nm}$ ). Inorganic compounds are included in the plastic formulation as additives to improve 273 some of the material properties like $\mathrm{CaCO}_{3}$ particles that are used as plastic fillers. These 274 particles were randomly distributed in the carbon matrix and were also found in the 275 mesoplastics, so there is no evidence for their leaching upon weathering. Some deep cracks 
were observed, filled with sea salt crystals (Figure 5c and SI 11) Numerous nanoparticles were

277 detected on $\mathrm{M}_{2}$ external face (Figure 5a). The nanoparticles contained high amounts of Fe. Iron 278 was systematically present with $\mathrm{Mn}, \mathrm{Ni}$ and $\mathrm{Zn}$ (Figure SI 12 and 13). These observations 279 confirm the occurrence of a recently described process $^{25}$ : the formation of Fe or Mn precipitated 280 minerals on plastic debris surfaces in the ocean. It was also demonstrated that polymer oxidation 281 promotes metal sorption ${ }^{25}$. It is noticeable to mention that high amounts of $\mathrm{Pb}$ was detected in 282 bulk $\mathrm{M}_{1}$ and EDS-TEM revealed the presence of elongated $\mathrm{Pb}$ particles with a size between 100 283 and $200 \mathrm{~nm}$ (Figure SI 14 and 15).

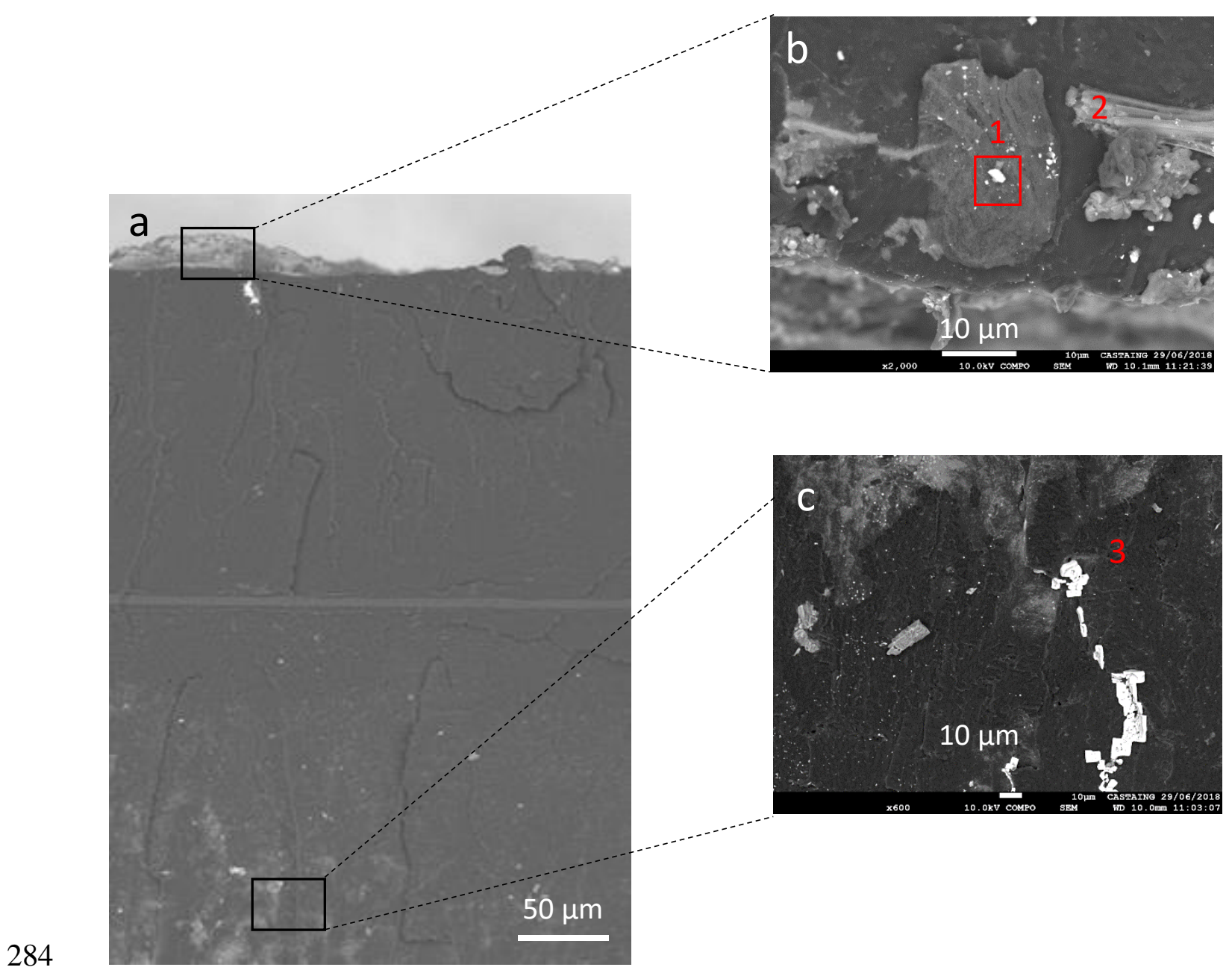

285 Figure 5: EDS-SEM observations of $\mathrm{M}_{2}$. a: view of the whole transverse section, b: 286 magnification of a part of the external face, c: magnification of deep cracks filled with sea salt 
crystals. The multilayer structure of the polymer is elucidated by EDX-SEM (Figure SI 16) and 288 is composed of ethylene vinyl alcohol copolymer.

289 As a conclusion, the microstructure investigation of ocean-weathered mesoplastics compared to original items has highlighted strong morphological, structural and molecular modifications

291 of the outer layer of the material. We also could observe that the outer side was more altered 292 certainly because more exposed to UV. Whereas bulk characterization did not allow to detect 293 deep modifications. The microstructure investigation showed that the outer layers of the debris 294 were remarkably more crystalline than the rest of the material. This outer layer consisted also of very shorten and highly oxidized polyethylene macromolecules. All these modifications are expected to eventually affect the mechanical properties of the polymer and lead to embrittlement ${ }^{48-50}$. Embrittlement, fragmentation and delamination of the affected surface layer 298 are most likely linked with the non-homogeneous erosion of the surface layer, leading to a 299 strong increase in the surface roughness. The spatial distributions of oxidation and roughening 300 are on the same scale as the polymer semi-crystalline microstructure (micrometre). This process 301 mainly involves fragmentation into $\mu$ Ps and NPs, which explains the significant thickness 302 decrease of the mesoplastics. The generation of NPs from microplastics was observed by 303 Gigault et al. ${ }^{11}$. This study also demonstrated the strong sorption of organic and inorganic 304 chemicals, mostly localized on the outer layer. The field of NP investigation is new, and there 305 is no description of the molecular structure of nanoplastics. What are NPs are made of? How 306 are the macromolecules organized in NPs? As $\mu$ Ps and NPs result from fragmentation of the 307 outer layer of macrodebris, their structure is certainly similar to that of the outer layer. The 308 present study provides insight into the structure of $\mu$ Ps and NPs. We conclude that $\mu$ Ps and NPs 309 are certainly composed of macromolecules that differ greatly from those composing plastics; these macromolecules are highly oxidized and significantly shorter. We also conclude that NPs 
311 interact with species like trace metals or organic compounds originating from sorption on

312 plastic debris surfaces. Overall, NP structural investigations must be conducted, or it will not

313 be possible to understand their fate in oceans or their potential impact on ecosystem and human

314 health.

315

\section{ASSOCIATED CONTENT}

Supporting Information Additional experimental details, including a photo of the macrodebris and the GPS coordinates were they have been collected. The characterization of $\mathrm{M}_{1}$ and $\mathrm{I}_{1}$ by AFM, AFMIR, calorimetry, GPC and fluorescence microscopy. Additional SEM, EDX-SEM and EDX-TEM data are also presented in the Supplementary Information in Figure SI 1 to 15 and Table SI 1

\section{Funding Sources}

This project is supported by the Total Corporate Foundation Foundation and The French National Reaserch Program for Environmental and Occupational Health of Anses (EST/2017/1/219).

\section{ACKNOWLEDGEMENT}

We thank the $7^{\text {th }}$ Continent Expedition association, as well as the staff and crew, for the sea sampling campaign.

\section{REFERENCES}

1. Geyer, R.; Jambeck, J.; Lavender Law, K. Production, use, and fate of all plastics ever made. Science Advances 2017, (7).

2. Andrady, A. L. Microplastics in the marine environment. Mar Pollut Bull 2011, 62 (8), 1596-1605.

3. Song, Y. K.; Hong, S. H.; Jang, M.; Kang, J. H.; Kwon, O. Y.; Han, G. M.; Shim, W. J. Large Accumulation of Micro-sized Synthetic Polymer Particles in the Sea Surface Microlayer. Environ Sci Technol 2014, 48 (16), 9014-9021.

4. Thompson, R. C.; Olsen, Y.; Mitchell, R. P.; Davis, A.; Rowland, S. J.; John, A. W. G.; 
McGonigle, D.; Russell, A. E. Lost at sea: Where is all the plastic? Science 2004, 304 (5672), 838-838.

340 5. Ter Halle, A.; Jeanneau, L.; Martignac, M.; Jarde, E.; Pedrono, B.; Brach, L.; Gigault,

341 J. Nanoplastic in the North Atlantic Subtropical Gyre. Environ Sci Technol 2017, 51 (23), 342 13689-13697.

343 6. Gigault, J.; ter Halle, A.; Baudrimont, M.; Pascal, P. Y.; Gauffre, F.; Phi, T. L.; El Hadri, 1030-1034.

7. Mintenig, S. M.; Bauerlein, P. S.; Koelmans, A. A.; Dekker, S. C.; van Wezel, A. P. Closing the gap between small and smaller: towards a framework to analyse nano- and microplastics in aqueous environmental samples. Environmental Science-Nano 2018, 5 (7), 1640-1649.

8. Galloway, T. S.; Cole, M.; Lewis, C. Interactions of microplastic debris throughout the marine ecosystem. Nature Ecology \& Evolution 2017, 1 (5).

9. Rochman, C. M.; Kross, S. M.; Armstrong, J. B.; Bogan, M. T.; Darling, E. S.; Green, S. J.; Smyth, A. R.; Verissimo, D. Scientific Evidence Supports a Ban on Microbeads (vol 49, pg 10759, 2015). Environ. Sci. Technol. 2015, 49 (24), 14740-14740.

10. Lambert, S.; Wagner, M. Characterisation of nanoplastics during the degradation of polystyrene. Chemosphere 2016, 145, 265-268.

11. Gigault, J.; Pedrono, B.; Maxit, B.; Ter Halle, A. Marine plastic litter: the unanalyzed nano-fraction. Environmental Science-Nano 2016, 3 (2), 346-350.

12. Jambeck, J. R.; Geyer, R.; Wilcox, C.; Siegler, T. R.; Perryman, M.; Andrady, A.; Narayan, R.; Law, K. L. Plastic waste inputs from land into the ocean. Science 2015, 347 (6223), 768-771.

13. Bouwmeester, H.; Hollman, P. C. H.; Peters, R. J. B. Potential Health Impact of Environmentally Released Micro- and Nanoplastics in the Human Food Production Chain: Experiences from Nanotoxicology. Environ Sci Technol 2015, 49 (15), 8932-8947.

14. ter Halle, A.; Ladirat, L.; Gendre, X.; Goudouneche, D.; Pusineri, C.; Routaboul, C.; Tenailleau, C.; Duployer, B.; Perez, E. Understanding the Fragmentation Pattern of Marine Plastic Debris. Environ Sci Technol 2016, 50 (11), 5668-5675.

15. Arutchelvi, J.; Sudhakar, M.; Arkatkar, A.; Doble, M.; Bhaduri, S.; Uppara, P. V. Biodegradation of polyethylene and polypropylene. Indian J Biotechnol 2008, 7 (1), 9-22.

16. Andrady, A., Persistence of plastic litter in the oceans. In Marine anthropogenic litter, Bergmann, M.; Gutow, L.; Klages, M., Eds. Springer International Publishing: 2015; Vol. Part $1, \mathrm{pp}$ 57-72.

17. Ghaffar, A.; Scott, A.; Scott, G. Chemical and Physical Changes Occurring during Uv Degradation of High Impact Polystyrene. Eur Polym J 1975, 11 (3), 271-275.

18. Craig, I. H.; White, J. R.; Shyichuk, A. V.; Syrotynska, I. Photo-induced scission and crosslinking in LDPE, LLDPE, and HDPE. Polym. Eng. Sci. 2005, 45 (4), 579-587.

19. Perez, C. J.; Failla, M. D.; Carella, J. M. SSA study of early polyethylenes degradation stages. Effects of attack rate, of average branch length, and of backbone polymethylene sequences length distributions. Polym Degrad Stabil 2013, 98 (1), 177-183.

20. Hsu, Y. C.; Weir, M. P.; Truss, R. W.; Garvey, C. J.; Nicholson, T. M.; Halley, P. J. A fundamental study on photo-oxidative degradation of linear low density polyethylene films at embrittlement. Polymer 2012, 53 (12), 2385-2393.

21. Ter Halle, A.; Ladirat, L.; Martignac, M.; Mingotaud, A. F.; Boyron, O.; Perez, E. To what extent are microplastics from the open ocean weathered? Environ Pollut 2017, 227, 167 174.

22. Gewert, B.; Plassmann, M. M.; MacLeod, M. Pathways for degradation of plastic 
polymers floating in the marine environment. Environmental Science-Processes \& Impacts 2015, 17 (9), 1513-1521. 23. Jahnke, A.; Arp, H. P. H.; Escher, B. I.; Gewert, B.; Gorokhova, E.; Kuhnel, D.; Reducing Uncertainty and Confronting Ignorance about the Possible Impacts of Weathering Plastic in the Marine Environment. Environmental Science \& Technology Letters 2017, 4 (3), $85-90$.

24. Bouhroum, R.; Boulkamh, A.; Asia, L.; Lebarillier, S.; Ter Halle, A.; Syakti, A. D.; Doumenq, P.; Malleret, L.; Wong-Wah-chung, P. Concentrations and fingerprints of PAHs and PCBs adsorbed onto marine plastic debris from the Indonesian Cilacap coast and the North Atlantic gyre. Reg Stud Mar Sci 2019, 29.

25. Prunier, J.; Maurice, L.; Perez, E.; Gigault, J.; Wickmann, A. C. P.; Davranche, M.; ter Halle, A. Trace metals in polyethylene debris from the North Atlantic subtropical gyre. Environ Pollut 2019, 245, 371-379.

26. Crist, B.; Schultz, J. M. Polymer spherulites: A critical review. Prog Polym Sci 2016, $56,1-63$.

27. Rouillon, C.; Bussiere, P. O.; Desnoux, E.; Collin, S.; Vial, C.; Therias, S.; Gardette, J. L. Is carbonyl index a quantitative probe to monitor polypropylene photodegradation? Polym Degrad Stabil 2016, 128, 200-208.

28. Rios, L. M.; Jones, P. R.; Moore, C.; Narayan, U. V. Quantitation of persistent organic pollutants adsorbed on plastic debris from the Northern Pacific Gyre's "eastern garbage patch". Journal of Environmental Monitoring 2010, 12 (12), 2226-2236.

29. Hirai, H.; Takada, H.; Ogata, Y.; Yamashita, R.; Mizukawa, K.; Saha, M.; Kwan, C.; Moore, C.; Gray, H.; Laursen, D.; Zettler, E. R.; Farrington, J. W.; Reddy, C. M.; Peacock, E. E.; Ward, M. W. Organic micropollutants in marine plastics debris from the open ocean and remote and urban beaches. Mar Pollut Bull 2011, 62 (8), 1683-1692.

30. Turner, A.; Solman, K. R. Analysis of the elemental composition of marine litter by field-portable-XRF. Talanta 2016, 159, 262-271.

31. Dazzi, A.; Prater, C. B.; Hu, Q. C.; Chase, D. B.; Rabolt, J. F.; Marcott, C. AFM-IR: Combining Atomic Force Microscopy and Infrared Spectroscopy for Nanoscale Chemical Characterization. Appl Spectrosc 2012, 66 (12), 1365-1384.

32. Gardette, M.; Perthue, A.; Gardette, J. L.; Janecska, T.; Foldes, E.; Pukanszky, B.; Therias, S. Photo- and thermal-oxidation of polyethylene: Comparison of mechanisms and influence of unsaturation content. Polym Degrad Stabil 2013, 98 (11), 2383-2390.

33. Krimm, S.; Liang, Y.; G., S. Infrared spectra of high polymers. II. polyethylene. The journal of chemical physics 1955, 25 (3), 549.

34. Tobin, M. C.; Carrano, M. J. Infrared spectra of polymers. I. Effect of crystallinity on the infrared spectrum of polyethylene and on the infrared spectra of nylon 6 and nylon 11. The journal of chemical physics 1956, 25 (5), 1044.

35. Guadagno, L.; Naddeo, C.; Vittoria, V.; Camino, G.; Cagnani, C. Chemical and morphologial modifications of irradiated linear low density polyethylene (LLDPE). Polym Degrad Stabil 2001, 72 (1), 175-186.

36. Wunderlich, B. Molecular Nucleation and Segregation. Faraday Discuss 1979, 68, 239+ .

37. Anwar, M.; Schilling, T. Crystallization of polyethylene: A molecular dynamics simulation study of the nucleation and growth mechanisms. Polymer 2015, 76, 307-312.

38. Sadler, D. M. New Explanation for Chain Folding in Polymers. Nature 1987, 326 (6109), 174-177.

39. Labana, S.; Labana, L. L. Quinacridones. Chemical Reviews 1967, 67, 1. 
40. Suhrhoff, T. J.; Scholz-Bottcher, B. M. Qualitative impact of salinity, UV radiation and turbulence on leaching of organic plastic additives from four common plastics - A lab experiment. Mar Pollut Bull 2016, 102 (1), 84-94.

439 41. Cisneros, R. L.; Espinoza, A. G.; Litter, M. I. Photodegradation of an azo dye of the textile industry. Chemosphere 2002, 48 (4), 393-399. 42. Kataoka, H.; Ise, M.; Narimatsu, S. Automated on-line in-tube solid-phase microextraction coupled with high performance liquid chromatography for the analysis of bisphenol A, alkylphenols, and phthalate esters in foods contacted with plastics. J Sep Sci 2002, 25 (1-2), 77-85.

43. Cooper, J. E.; Kendig, E. L.; Belcher, S. M. Assessment of bisphenol A released from reusable plastic, aluminium and stainless steel water bottles. Chemosphere 2011, 85 (6), 943 947.

448 44. Lin, E. L. C.; Cormier, S. M.; Torsella, J. A. Fish biliary polycyclic aromatic hydrocarbon metabolites estimated by fixed-wavelength fluorescence: Comparison with HPLC-fluorescent detection. Ecotox Environ Safe 1996, 35 (1), 16-23.

45. Nahorniak, M. L.; Booksh, K. S. Excitation-emission matrix fluorescence spectroscopy in conjunction with multiway analysis for PAH detection in complex matrices. Analyst 2006, 131 (12), 1308-1315.

46. Butler, H. T.; Coddens, M. E.; Khatib, S.; Poole, C. F. Determination of Polycyclic Aromatic-Hydrocarbons in Environmental-Samples by High-Performance Thin-Layer Chromatography and Fluorescence Scanning Densitometry. J Chromatogr Sci 1985, 23 (5), 200-207.

458 47. Hoge, F. E.; Vodacek, A.; Blough, N. V. Inherent Optical-Properties of the Ocean Retrieval of the Absorption-Coefficient of Chromophoric Dissolved Organic-Matter from Fluorescence Measurements. Limnol Oceanogr 1993, 38 (7), 1394-1402.

48. Fayolle, B.; Richaud, E.; Colin, X.; Verdu, J. Review: degradation-induced embrittlement in semi-crystalline polymers having their amorphous phase in rubbery state. $J$ Mater Sci 2008, 43 (22), 6999-7012.

49. White, J. R.; Turnbull, A. Weathering of Polymers - Mechanisms of Degradation and Stabilization, Testing Strategies and Modeling. J Mater Sci 1994, 29 (3), 584-613.

50. White, J. R. Polymer ageing: physics, chemistry or engineering? Time to reflect. $\mathrm{Cr}$ Chim 2006, 9 (11-12), 1396-1408. 